\title{
Acinetobacter beijerinckii sp. nov. and Acinetobacter gyllenbergii sp. nov., haemolytic organisms isolated from humans
}

\author{
Alexandr Nemec, ${ }^{1}$ Martin Musílek, ${ }^{1}$ Martina Maixnerová, ${ }^{1}$ \\ Thierry De Baere, ${ }^{2}$ Tanny J. K. van der Reijden, ${ }^{3}$ Mario Vaneechoutte ${ }^{2}$ \\ and Lenie Dijkshoorn ${ }^{3}$ \\ ${ }^{1}$ Centre of Epidemiology and Microbiology, National Institute of Public Health, Šrobárova 48, 100 \\ 42 Prague 10, Czech Republic \\ ${ }^{2}$ Department of Clinical Chemistry, Microbiology and Immunology, University Hospital, Blok A, \\ B-9000 Ghent, Belgium \\ ${ }^{3}$ Department of Infectious Diseases, Leiden University Medical Centre C5-P, PO Box 9600, 2300 \\ RC Leiden, The Netherlands
}

Correspondence

Alexandr Nemec anemec@szu.cz

\begin{abstract}
The taxonomic status of 24 haemolytic, non-glucose acidifying Acinetobacter strains that did not belong to any previously described species was investigated by means of a polyphasic approach. Using AFLP fingerprinting, amplified rDNA restriction analysis and phenotypic characterization, the strains were classified into two phenetically coherent groups (comprising 15 and 9 strains) that were distinct from each other and from all known Acinetobacter species. Confirmation that these groups formed two separate lineages within the genus Acinetobacter was obtained from comparative analysis of partial sequences of the gene encoding the $\beta$-subunit of RNA polymerase in all strains and also from 16S rRNA gene sequence analysis of representative strains.

Previously published DNA-DNA reassociation data for some of the strains used also supported the species rank for both groups, for which the names Acinetobacter beijerinckii sp. nov. and Acinetobacter gyllenbergii sp. nov. are proposed. The strains of $A$. beijerinckii sp. nov. originated from human and animal specimens and from various environmental sources, whereas those of $A$. gyllenbergii sp. nov. were isolated exclusively from human clinical specimens. The phenotypic characteristics most useful for the differentiation of these species from other Acinetobacter species that comprise haemolytic strains were the inability of $A$. beijerinckii sp. nov. to grow on L-arginine and the ability of $A$. gyllenbergii sp. nov. to grow on azelate. The type strain of $A$. beijerinckii sp. nov. is NIPH $838^{\top}$ ( $=\mathrm{LUH} 4759^{\top}=$ CCUG $51249^{\top}=\mathrm{CCM} 7266^{\top}=58 \mathrm{a}^{\top}$ ) and the type strain of $A$. gyllenbergii sp. nov. is NIPH $2150^{\top}\left(=\mathrm{RUH} 422^{\top}=\right.$ CCUG $51248^{\top}=\mathrm{CCM}$ $7267^{\top}=1271^{\top}$ ).
\end{abstract}

The genus Acinetobacter currently comprises 32 genomic species, of which the names of 17 have been validly published (Dijkshoorn et al., 2007). Some Acinetobacter strains are able both to lyse mammalian erythrocytes and to

Abbreviations: ARDRA, amplified rDNA restriction analysis.

The GenBank/EMBL/DDBJ accession numbers for the rpoB partial gene sequences determined in this study are EU477105-EU477158 and those for the 16S rRNA gene sequences of strains NIPH $838^{\top}$, LUH 6214, NIPH 2150', LUH 1740 and LUH 1737 are AJ626712, AJ303013, AJ293694, AJ293693 and AJ293692, respectively.

Detailed data on the origins of the $A$. beijerinckii sp. nov. and $A$. gyllenbergii sp. nov. strains and a dendrogram derived from a cluster analysis of AFLP fingerprints are available as supplementary material with the online version of this paper. liquefy gelatin. These features have been associated with particular species and therefore are taxonomically relevant. Acinetobacter haemolyticus, 'Acinetobacter venetianus' and genomic species 6,13BJ (=14TU), 14BJ, 15BJ, 16 and 17 comprise strains that are typically both proteolytic and haemolytic (Bouvet \& Grimont, 1986; Bouvet \& Jeanjean, 1989; Gerner-Smidt et al., 1991; Vaneechoutte et al., 1999). In contrast, strains of the other known genomic species are usually neither proteolytic nor haemolytic (Bouvet \& Grimont, 1986; Tjernberg \& Ursing, 1989; Nemec et al., 2001, 2003; Carr et al., 2003); Acinetobacter junii is an exception, as a significant proportion of its strains are haemolytic but non-proteolytic (Gerner-Smidt et al., 1991). 
Recently, we identified two phenotypically and genotypically distinct groups of Acinetobacter strains that did not belong to any of the described species. All these strains produced strong haemolysis on agar media supplemented with sheep erythrocytes. Some of them have already been subjected to DNA-DNA hybridization by others and were shown not to belong to any of the species known at that time (Bouvet \& Grimont, 1986; Tjernberg \& Ursing, 1989; Bouvet \& Jeanjean, 1989). In this study, we present the results of phenotypic characterization, AFLP fingerprinting and comparative analysis of the RNA polymerase $\beta$-subunit $(r p o B)$ and 16S rRNA gene sequences of the organisms of the two groups, and discuss these results in the light of previously published DNA-DNA reassociation data. We conclude that both groups are genetically coherent and distinct from each other and from all hitherto known genomic species and propose the names Acinetobacter beijerinckii sp. nov. and Acinetobacter gyllenbergii sp. nov. for these groups.

The 24 strains of $A$. beijerinckii sp. nov. $(n=15)$ and $A$. gyllenbergii sp. nov. $(n=9)$ investigated in this study are listed in Supplementary Table S1 (available in IJSEM Online). All of the strains studied had the properties of the genus Acinetobacter (Baumann et al., 1968), i.e. they were Gram-negative, strictly aerobic, oxidase-negative, nonmotile coccobacilli that were positive in the transformation assay of Juni (1972). Additionally, 29 strains representing all described Acinetobacter genomic species, which are known to contain haemolytic and/or proteolytic strains, were selected from previous studies for comparative taxonomic analysis (Supplementary Fig. S1, available in IJSEM Online). Finally, the type or reference strains of the remaining non-haemolytic species of the genus were included in the genotypic analyses (Figs 1 and 2), except Acinetobacter grimontii, which has recently been shown to be a later synonym of A. junii (Vaneechoutte et al., 2008).

AFLP analysis was used as the main genome fingerprinting method to assess the overall genotypic similarity of strains at species level (Nemec et al., 2001). The result of the comparative analysis of the AFLP patterns of the strains of A. beijerinckii sp. nov. and A. gyllenbergii sp. nov. and of those representing known Acinetobacter species is shown in Supplementary Fig. S1. The strains of A. beijerinckii sp. nov. and A. gyllenbergii sp. nov. grouped into two clusters at similarity levels of 53 and $72 \%$, respectively, i.e. above the $50 \%$ level that was determined in previous studies as the threshold for the delineation of Acinetobacter species (Nemec et al., 2001, 2003). The two clusters were separate from each other and from all other strains at similarity cut-off levels $\leqslant 37 \%$. These results indicate both the genomic coherence and the distinctness of each of the two novel species.

Comparative sequence analysis of the $r p o B$ gene was used to confirm the intraspecies relatedness of strains of $A$. beijerinckii sp. nov. and A. gyllenbergii sp. nov. and their separation from each other and from all hitherto described Acinetobacter species. The method of La Scola et al. (2006) was followed with minor modifications. Two sets of primers were used to amplify two variable regions of the rpoB gene: zone 1, spanning nucleotide positions 29163267 [primers Ac696F (5'-TAYCGYAAAGAYTTGAAAGAAG-3') and Ac1093R (5'-CMACACCYTTGTTMCCRTGA-3')], and zone 2, spanning nucleotide positions 3263-3773 [primers Ac1055F (5'-GTGATAARATGGCBGGTCGT-3') and Ac1598R (5'-CGBGCRTGCATYTTGTCRT-3')] (La Scola et al., 2006). PCR amplification was performed in $20 \mu \mathrm{l}$ containing $10 \mu \mathrm{l}$ Taq PCR Master Mix (Qiagen), $0.2 \mu \mathrm{M}$ each primer and $1.5 \mu \mathrm{l}$ DNA suspension obtained by alkaline lysis as described by Nemec et al. (2000), with the following cycling conditions: $94{ }^{\circ} \mathrm{C}$ for $2 \mathrm{~min} ; 32$ cycles of $30 \mathrm{~s}$ at $94{ }^{\circ} \mathrm{C}, 30 \mathrm{~s}$ at $55^{\circ} \mathrm{C}$ and $2 \mathrm{~min}$ at $72{ }^{\circ} \mathrm{C}$; and $5 \mathrm{~min}$ at $72{ }^{\circ} \mathrm{C}$. Sequencing reactions were carried out with a BigDye Terminator cycle sequencing kit (Applied Biosystems) using the aforementioned primers. Sequencing products were analysed using an ABI Prism 3100 genetic analyzer (Applied Biosystems) and edited using the program LASERGENE (DNASTAR). Comparative sequence analysis was performed using the BioNumerics 5.0 software package (Applied Maths). First, a similarity matrix based on pairwise alignment of sequences was calculated using the UPGMA clustering algorithm; this was followed by multiple sequence alignment and global cluster analysis using the Jukes-Cantor algorithm (to calculate evolutionary distances; Jukes \& Cantor, 1969) and the neighbour-joining clustering method. The calculations were carried out for concatenated zones 1 and 2 using nucleotide positions $2917-3267$ for zone 1 and positions $3322-3723$ for zone 2 . The position numbers correspond to those of the $r p o B$ encoding sequence of Acinetobacter baumannii (La Scola et al., 2006).

Partial sequences for $r p o B$ were determined for all of the strains of $A$. beijerinckii sp. nov. and A. gyllenbergii sp. nov. as well as for the type or reference strains representing all known Acinetobacter genomic species. Twenty-two strains used by La Scola et al. (2006) were resequenced in the present study: the results were identical to those of La Scola et al. (2006). The only discrepancies, found for the $r p o B$ sequences of genomic species 13TU, CIP 70.18 and genomic species 16, CIP 64.2, could be explained by the confusion between the designations of these two strains in the Collection of the Pasteur Institute (CIP; Paris, France) from which the strains had been obtained by La Scola et al. (2006) (this error has been corrected by the CIP). The results of the cluster analysis of concatenated $r p o B$ zones 1 and 2 are shown in Fig. 1 . The strains of $A$. beijerinckii and A. gyllenbergii spp. nov. grouped into two respective clusters with bootstrap values supporting the monophyly of each of these clusters. The intraspecies similarity values (expressed as the percentages of identical nucleotides in corresponding positions in two aligned sequences) for the strains of A. beijerinckii sp. nov. and A. gyllenbergii sp. nov. ranged from 97.9 to $100 \%$ and 98.8 to $100 \%$, respectively, whereas the interspecies similarity values between the strains of A. beijerinckii and A. gyllenbergii spp. nov. and 


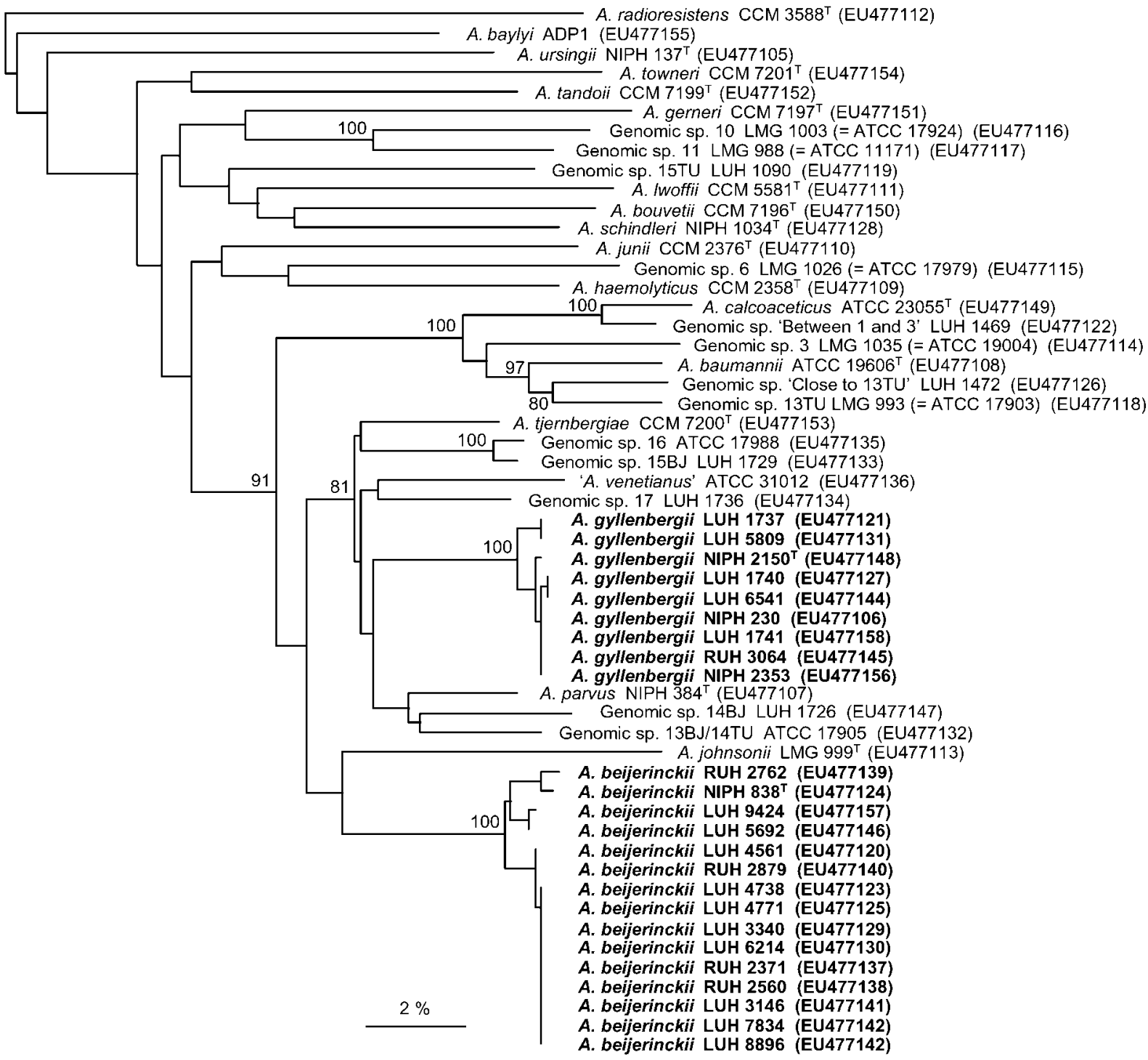

Fig. 1. Neighbour-joining tree, based on two concatenated variable zones of rpoB of Acinetobacter beijerinckii sp. nov. Acinetobacter gyllenbergii sp. nov. and representatives of known species of the genus Acinetobacter. Numbers at branch points are bootstrap percentages (based on 1000 resamplings) $>80 \%$. GenBank accession numbers are given in parentheses. Bar, $2 \%$ sequence divergence.

other members of the genus Acinetobacter were 78.2-91.6 and $78.6-93.9 \%$, respectively.

The 16S rRNA gene sequence analysis was performed as described previously (Nemec et al., 2001) and included comparative analysis of the almost-complete $16 \mathrm{~S}$ rRNA gene sequences as well as amplified $16 \mathrm{~S}$ rDNA restriction analysis (ARDRA), which is based on restriction enzyme digestion of the PCR-amplified 16S rRNA gene with restriction endonucleases. Almost-complete 16S rRNA gene sequences were obtained for A. beijerinckii sp. nov. strains NIPH $838^{\mathrm{T}}$ and LUH 6214 and for A. gyllenbergii sp. nov. strains NIPH $2150^{\mathrm{T}}$, LUH 1737 and LUH 1740. The sequences clustered with those of other members of the genus Acinetobacter (Fig. 2). The sequences of the two A. beijerinckii sp. nov. strains were identical, as were those of the three A. gyllenbergii sp. nov. strains. The similarity between the sequences of $A$. beijerinckii sp. nov. and those of other members of the genus Acinetobacter ranged from 95.0 (Acinetobacter towneri) to $99.3 \%$ (genomic species 16). The similarity values between the $16 \mathrm{~S}$ rRNA gene sequences of $A$. gyllenbergii sp. nov. and those of other members of the genus ranged from 94.6 (A. towneri) to $99.1 \%$ (genomic species 16). The sequence similarity between $A$. beijerinckii sp. nov. and A. gyllenbergii sp. nov. was $98.6 \%$. To estimate the intraspecies sequence 


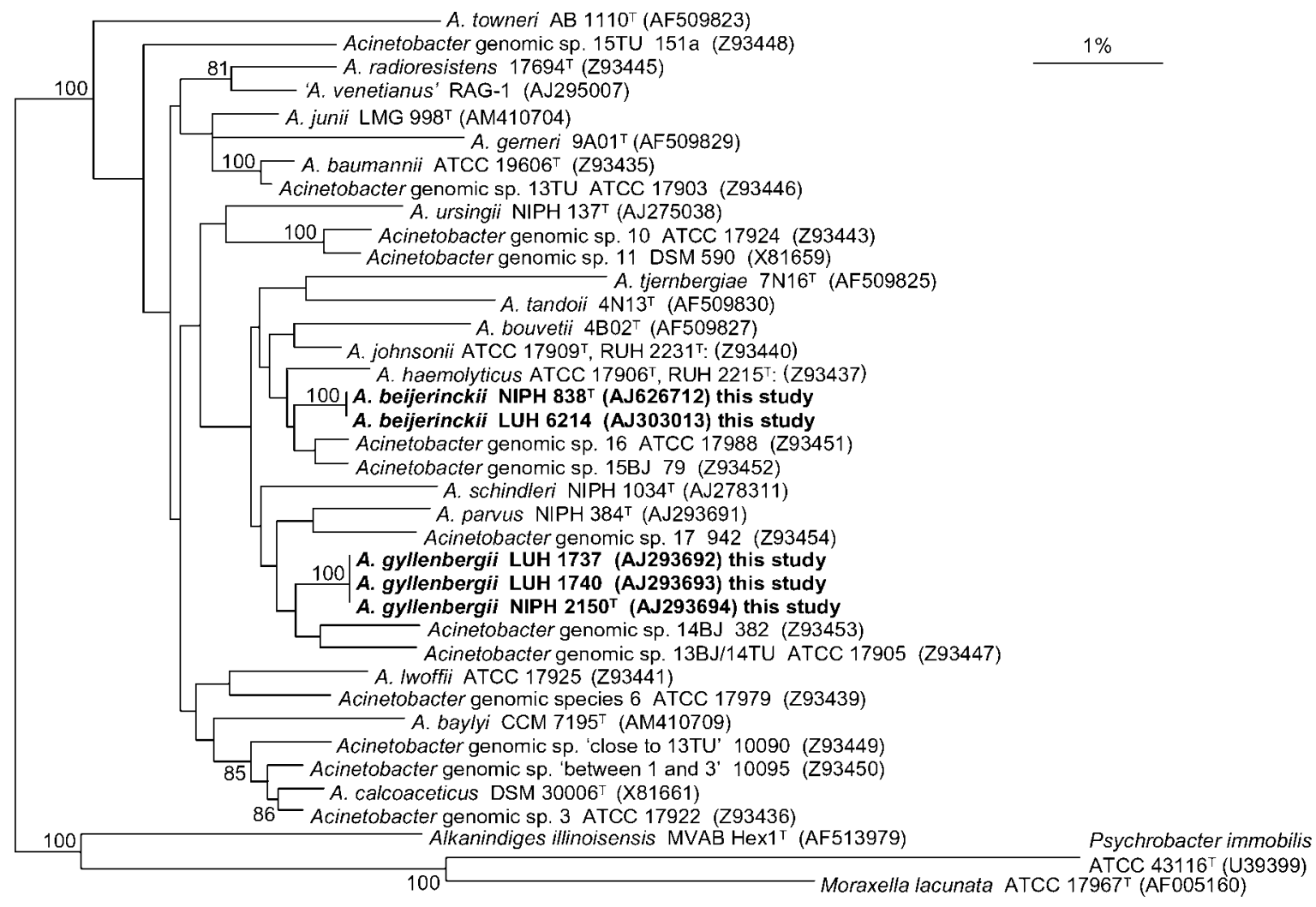

Fig. 2. Rooted tree, based on $16 \mathrm{~S}$ rRNA gene sequences, showing the relationships of Acinetobacter beijerinckii sp. nov. and Acinetobacter gyllenbergii sp. nov. with respect to members of the genus Acinetobacter and representatives of the most closely related genera. The cluster analysis, performed using GENEBASE (Applied Maths), was based on the neighbour-joining method, using Psychrobacter immobilis as the outgroup, an open gap penalty of $100 \%$ and a unit gap cost of $20 \%$. The region used corresponds to Escherichia coli positions 99-1470. Bootstrap percentages (based on 100 simulations) >80\% are shown. GenBank accession numbers are given in parentheses. Bar, $1 \%$ sequence divergence.

homogeneity of the $16 \mathrm{~S}$ rRNA gene, ARDRA was performed for all strains of both species. On the basis of the ARDRA numbering system of Dijkshoorn et al. (1998), all $A$. beijerinckii sp. nov. strains had the restriction pattern CfoI 1, AluI 4, MboI 2, RsaI 2, MspI 2 and BfaI 14, whereas the A. gyllenbergii sp. nov. strains shared the pattern $C f_{o I} 1$, AluI 4, MboI 1, RsaI 4 and MspI 3.

Some strains included in this study have been investigated previously, using DNA-DNA hybridization (Supplementary Table S1, available in IJSEM Online). $A$. beijerinckii sp. nov. strain LUH 4738 [strain 83 in the study of Bouvet \& Grimont (1986)] was found to be less than $34 \%$ similar to the type or reference strains of the first 12 genomic species described by Bouvet \& Grimont (1986) and was only $11-22 \%$ similar to the proteolytic genomic species 13BJ, 14BJ, 15BJ, 16 and 17 (Bouvet \& Jeanjean, 1989). Two other A. beijerinckii sp. nov. strains [NIPH $838^{\mathrm{T}}$ $\left(=58 \mathrm{a}^{\mathrm{T}}\right)$, LUH $\left.4771(=190)\right]$ remained ungrouped in the study of Tjernberg \& Ursing (1989), while Seifert et al. (1997) could not allocate strain LUH 3340 (=SH 139) to any of the 15 genomic species originally studied by
Tjernberg \& Ursing (1989). A. gyllenbergii sp. nov. strain LUH 1737 (=80) was shown to be less than $34 \%$ similar to the type or reference strains of Acinetobacter calcoaceticus, A. haemolyticus, A. junii, Acinetobacter lwoffii, Acinetobacter johnsonii and genomic species 6, 9, 10, 11 and 12 (Bouvet \& Grimont, 1986) and to be only $43-55 \%$ similar to the proteolytic genomic species 13BJ, 14BJ, 15BJ, 16 and 17, with $\Delta T_{\mathrm{m}}$ ranging from 6.5 to $9.5{ }^{\circ} \mathrm{C}$ (Bouvet \& Jeanjean, 1989). Similarly, three other $A$. gyllenbergii sp. nov. strains [NIPH $2150^{\mathrm{T}}\left(=1271^{\mathrm{T}}\right)$, LUH 1740 (=930), LUH 1741 $(=944)]$ were found to be $28-55 \%$ similar to genomic species $13 \mathrm{BJ}, 14 \mathrm{BJ}, 15 \mathrm{BJ}, 16$ and 17 , with $\Delta T_{\mathrm{m}}$ ranging from 6.5 to $12{ }^{\circ} \mathrm{C}$ (Bouvet \& Jeanjean, 1989). These archive data indicate that both $A$. beijerinckii and A. gyllenbergii spp. nov. are distinct from 18 genomic species described by Bouvet \& Grimont (1986), Tjernberg \& Ursing (1989) and Bouvet \& Jeanjean (1989). As the results of both AFLP and comparative sequence analysis of housekeeping genes (16S rRNA gene, $r p o B$ ) did not indicate a close relationship between the novel species and species described by Nemec et al. (2001, 2003) and Carr et al. (2003), additional DNADNA hybridization studies were not carried out. 
The results of phenotypic tests are given in the species descriptions. The tests used were those described by Nemec et al. (2000), with some modifications and additions. The cultivation temperature was $30{ }^{\circ} \mathrm{C}$ and tests were evaluated after 2 days incubation, unless indicated otherwise. Aerobic acid production from glucose was tested using Hugh and Leifson's agar (OF basal medium; Merck) supplemented with $1 \%(\mathrm{w} / \mathrm{v})$ D-glucose. The gelatinase test was performed on tryptone soya agar (Oxoid) containing $4 \%$ $(\mathrm{w} / \mathrm{v})$ gelatin, with Frazier's reagent $\left(15 \%, \mathrm{w} / \mathrm{v}, \mathrm{HgCl}_{2}\right.$ in $20 \%, v / v, \mathrm{HCl}$ ) being used to visualize zones of gelatin hydrolysis. Haemolysis was tested on Columbia agar plates supplemented with $5 \%$ sheep or horse blood (bioMérieux). Growth tests at 25, 30,35, 37 and $41{ }^{\circ} \mathrm{C}$ were performed in $5 \mathrm{ml}$ aliquots of brain-heart infusion broth (Oxoid) dispensed into tubes ( $16 \mathrm{~mm}$ inner diameter). Each tube was inoculated with a drop $(\sim 30 \mu \mathrm{l})$ of cell suspension of standardized turbidity $\left(\sim 10^{8}\right.$ c.f.u. $\left.\mathrm{ml}^{-1}\right)$ prepared in saline from an overnight agar culture and incubated in a thermostatically controlled water bath. Utilization of citrate was tested on Simmons' citrate agar (Oxoid) and was recorded after 2, 4 and 6 days incubation. Tests for the assimilation of the other 32 carbon sources were performed using the basal mineral medium of Cruze et al. (1979) supplemented with $0.1 \%(\mathrm{w} / \mathrm{v})$ carbon source. The basal medium consisted of the following $\left(1^{-1}\right): 10.0 \mathrm{~g} \mathrm{KH}_{2} \mathrm{PO}_{4}$, $5.0 \mathrm{~g} \mathrm{Na}_{2} \mathrm{HPO}_{4}, 2.0 \mathrm{~g}\left(\mathrm{NH}_{4}\right)_{2} \mathrm{SO}_{4}, 0.2 \mathrm{~g} \mathrm{MgSO}_{4} .7 \mathrm{H}_{2} \mathrm{O}$, $0.001 \mathrm{~g} \mathrm{CaCl}_{2} \cdot 2 \mathrm{H}_{2} \mathrm{O}$ and $0.001 \mathrm{~g} \mathrm{FeSO}_{4} \cdot 7 \mathrm{H}_{2} \mathrm{O}$ (pH 7.0). The supplemented medium was dispensed into tubes (12 $\mathrm{mm}$ inner diameter) in $3 \mathrm{ml}$ volumes and was inoculated as in the growth-temperature tests. Growth on carbon sources was evaluated after 2, 4, 6 and 10 days by means of visual comparison between inoculated tubes containing carbon sources and control tubes containing only inoculated basal medium. A. baumannii NIPH 146 was used as a positive control for all assimilation tests except those for histamine and tryptamine (positive control: Acinetobacter genomic species 11 LMG 988) and those for D-glucose and D-gluconate (positive control: Acinetobacter baylyi CCM $7195^{\mathrm{T}}$ ). All phenotypic tests were performed three times in different sessions and were repeated when inconsistent results were obtained.

All of the strains of $A$. beijerinckii sp. nov. and $A$. gyllenbergii sp. nov. produced large zones of haemolysis after $24 \mathrm{~h}$ on agar media supplemented with sheep or horse erythrocytes; haemolysis was greater at a cultivation temperature of $37^{\circ} \mathrm{C}$. Notably, A. gyllenbergii sp. nov. strain NIPH 2353 (=CCM 1976) was used by Lehmann (1973) in a study on the haemolytic properties of eight Acinetobacter sp. strains. His results suggested that an extracellular cytolytic protein was responsible for the haemolysis. In addition, the strains could be classified into two groups on the basis of the data from detailed biochemical characterization of their haemolytic properties. Whereas the strains of the first group showed direct haemolysis, with no detectable increase in lysis after cooling, the strains of the second group exhibited hot- cold haemolysis. The two types of haemolytic activities were also associated with immunological differences. As five of the strains used by Lehmann were available at the Czech Collection of Microorganisms (Brno, Czech Republic), we attempted to identify these strains at the species level. The three strains (CCM 1989, CCM $2358^{\mathrm{T}}$ and CCM 2359) with hot-cold haemolysis were allocated to A. haemolyticus, whereas the two strains showing direct haemolysis were identified as A. gyllenbergii sp. nov. (CCM 1976) and genomic species 13BJ (CCM 2357=ATCC 17905). These results suggest that the differences in haemolytic activity have taxonomic relevance.

A. beijerinckii sp. nov. and A. gyllenbergii sp. nov. could be phenotypically differentiated from other non-haemolytic Acinetobacter genomic species by the ability to lyse sheep erythrocytes or, in the case of A. gyllenbergii sp. nov. by gelatinase activity, and on the basis of the results of some other biochemical tests described by Bouvet \& Grimont (1987) (e.g. tests for acid production from glucose and utilization of trans-aconitate, glutarate, L-aspartate, $\beta$ alanine, L-histidine and L-phenylalanine). Table 1 shows phenotypic characteristics useful for the differentiation of $A$. beijerinckii sp. nov. and A. gyllenbergii sp. nov. from each other and from all of the species that include haemolytic strains. The 10 tests shown were selected to provide reliable discrimination in terms of reproducibility and ease of interpretation of results. For A. beijerinckii sp. nov. the number of discriminative tests ranged from nine (genomic species $14 \mathrm{BJ}$ ) to two (A. haemolyticus, 'A. venetianus') whereas for A. gyllenbergii sp. nov. this number ranged from six (A. beijerinckii sp. nov., genomic species 6) to two (genomic species 14BJ, genomic species 16). The most useful characteristics for the differentiation of these species from the other haemolytic Acinetobacter species were the inability of $A$. beijerinckii sp. nov. to grow on L-arginine and the ability of $A$. gyllenbergii sp. nov. to grow on azelate. While the former feature was observed only in strains of $A$. beijerinckii sp. nov., the latter was confined to A. gyllenbergii sp. nov. and genomic species 14BJ. Both of the novel species could be identified genotypically using $r p o B$ sequence analysis or AFLP library fingerprinting. Finally, strains of $A$. beijerinckii sp. nov. and A. gyllenbergii sp. nov. had ARDRA profiles (see above) that are unique among the species studied to date (Dijkshoorn et al., 1998; Nemec et al., 2001, 2003).

\section{Description of Acinetobacter beijerinckii sp. nov.}

Acinetobacter beijerinckii [bei.je.rin'cki.i. N.L. masc. gen. n. beijerinckii of Beijerinck, named in honour of Martinus Willem Beijerinck (1851-1931), the Dutch microbiologist and botanist].

The description is based on the characterization of 15 strains (Supplementary Table S1 in IJSEM Online). Phenotypic characteristics correspond to those of the genus (Baumann et al., 1968), i.e. cells are Gram-negative, strictly aerobic, oxidase-negative, catalase-positive, nonmotile coccobacilli, capable of growth in mineral media 
Table 1. Phenotypic characteristics useful for distinguishing Acinetobacter beijerinckii sp. nov. and Acinetobacter gyllenbergii $\mathrm{sp}$. nov. from each other and from haemolytic strains of other species

Taxa: 1, A. beijerinckii sp. nov.; 2, A. gyllenbergii sp. nov.; 3, A. haemolyticus; 4, A. junii; 5, genomic species 6; 6, genomic species 13BJ/14TU; 7, genomic species 14BJ; 8, genomic species 15BJ; 9, genomic species 16; 10, genomic species 17; 11, 'A. venetianus'; 12, Acinetobacter tjernbergiae. The results shown were obtained in the present study. Strains of previously described genomic species were selected from the studies of Bouvet \& Grimont (1987), Tjernberg \& Ursing (1989), Janssen et al. (1997), Vaneechoutte et al. (1999) and Carr et al. (2003). All of them are indicated in Supplementary Fig. S1 (in IJSEM Online). The type strain of A. tjernbergiae was included as it revealed haemolysis when tested in our laboratory. Numbers of strains are indicated in parentheses. +, All strains positive within 4 days incubation; -, all strains negative within 10 days incubation; $\mathrm{v}$, strain-dependent results or weak, delayed or non-reproducible reactions.

\begin{tabular}{|c|c|c|c|c|c|c|c|c|c|c|c|c|}
\hline Characteristic & $\begin{array}{c}1 \\
(n=15)\end{array}$ & $\begin{array}{c}2 \\
(n=9)\end{array}$ & $\begin{array}{c}3 \\
(n=5)\end{array}$ & $\begin{array}{c}4 \\
(n=4)\end{array}$ & $\begin{array}{c}5 \\
(n=2)\end{array}$ & $\begin{array}{c}6 \\
(n=6)\end{array}$ & $\begin{array}{c}7 \\
(n=3)\end{array}$ & $\begin{array}{c}8 \\
(n=2)\end{array}$ & $\begin{array}{c}9 \\
(n=3)\end{array}$ & $\begin{array}{c}10 \\
(n=2)\end{array}$ & $\begin{array}{c}11 \\
(n=2)\end{array}$ & $\begin{array}{c}12 \\
(n=1)\end{array}$ \\
\hline $\begin{array}{l}\text { Acid from D-glucose } \\
\text { Utilization of: }\end{array}$ & - & - & $\mathrm{V}$ & - & + & + & + & - & - & - & - & - \\
\hline DL-Lactate & - & + & - & + & - & + & + & + & + & + & - & - \\
\hline Azelate & - & + & - & - & - & - & + & - & - & - & - & - \\
\hline$\beta$-Alanine & - & + & - & - & - & $\mathrm{V}$ & + & - & $\mathrm{V}$ & + & - & - \\
\hline L-Arginine & - & + & + & + & + & + & + & + & + & + & + & + \\
\hline Ethanol & + & $\mathrm{V}$ & $\mathrm{V}$ & $\mathrm{V}$ & + & - & - & - & - & - & + & + \\
\hline Benzoate & - & + & - & + & - & $\mathrm{V}$ & + & + & + & + & + & + \\
\hline Adipate & - & + & - & - & - & - & + & - & - & - & - & - \\
\hline Putrescine & - & - & - & - & - & - & + & - & - & + & - & - \\
\hline
\end{tabular}

with acetate as the sole carbon source and ammonia as the sole source of nitrogen but incapable of dissimilative denitrification. Positive in the transformation assay of Juni (1972). Colonies on tryptone soya agar after $24 \mathrm{~h}$ incubation at $30{ }^{\circ} \mathrm{C}$ are approximately $1.0-2.0 \mathrm{~mm}$ in diameter, circular, convex, smooth and slightly opaque with entire margins. Growth occurs at temperatures ranging from 25 to $37{ }^{\circ} \mathrm{C}$, but not at $41{ }^{\circ} \mathrm{C}$. Sheep and horse erythrocytes are lysed in $24 \mathrm{~h}$ at $30-37^{\circ} \mathrm{C}$. Acid is not produced from D-glucose; gelatin is hydrolysed by some (13\%) strains. Acetate, ethanol, citrate (Simmons'), 4-aminobutyrate, L-aspartate, L-histidine, D-malate and malonate are utilized as sole sources of carbon, with growth becoming visible after 2 days incubation. No growth occurs on DL-lactate, trans-aconitate, glutarate, azelate, $\beta$-alanine, histamine, L-phenylalanine, phenylacetate, levulinate, citraconate, 4-hydroxybenzoate, L-tartrate, L-ornithine, L-arginine, D-glucose, D-gluconate, D-ribose, L-arabinose, 2,3-butanediol, benzoate, adipate, gentisate, tryptamine, trigonelline, tricarballylate or putrescine within 10 days. L-Leucine is utilized by most $(93 \%)$ strains.

The strains studied were isolated from human (sputum, peritoneal dialysis fluid, gall, throat swab, perineal swab, faeces) and equine (airways) clinical specimens, from a hospital environment and staff (skin), and soil and water (Supplementary Table S1 in IJSEM Online). The type strain, NIPH $\quad 838^{\mathrm{T}} \quad\left(=\right.$ LUH $\quad 4759^{\mathrm{T}}=$ CCUG $\quad 51249^{\mathrm{T}}=$ CCM $\left.7266^{\mathrm{T}}=58 \mathrm{a}^{\mathrm{T}}\right)$, was isolated in 1980 from the wound of a patient at the hospital in Malmö, Sweden (Tjernberg \& Ursing, 1989). The type strain grows weakly on L-leucine and does not hydrolyse gelatin after 2 days incubation.

\section{Description of Acinetobacter gyllenbergii sp. nov.}

Acinetobacter gyllenbergii (gyl.len.ber' gi.i. N.L. masc. gen. n. gyllenbergii of Gyllenberg, named in honour of Helge G. Gyllenberg, the Finnish bacteriologist and taxonomist).

The description is based on the characterization of 9 strains (Supplementary Table S1 in IJSEM Online). Phenotypic characteristics correspond to those of the genus (Baumann et al., 1968), i.e. cells are Gram-negative, strictly aerobic, oxidase-negative, catalase-positive, non-motile coccobacilli, capable of growth in mineral media with acetate as the sole carbon source and ammonia as the sole source of nitrogen but incapable of dissimilative denitrification. Positive in the transformation assay of Juni (1972). Colonies on tryptone soya agar after $24 \mathrm{~h}$ incubation at $30{ }^{\circ} \mathrm{C}$ are approximately $1.0-2.0 \mathrm{~mm}$ in diameter, circular, convex, smooth and slightly opaque with entire margins. Growth occurs at temperatures ranging from 25 to $37^{\circ} \mathrm{C}$, but not at $41{ }^{\circ} \mathrm{C}$; weak growth of some strains occurs at $37{ }^{\circ} \mathrm{C}$. Sheep and horse erythrocytes are lysed in $24 \mathrm{~h}$ at $30-37{ }^{\circ} \mathrm{C}$. Acid is not produced from D-glucose; gelatin is hydrolysed by all strains. Acetate, citrate (Simmons'), DLlactate, azelate, $\beta$-alanine, L-histidine, D-malate, phenylacetate, L-arginine, L-leucine, benzoate and adipate are utilized as sole sources of carbon, with growth becoming visible after 2 days incubation. No growth occurs on transaconitate, L-aspartate, histamine, levulinate, citraconate, Ltartrate, D-glucose, D-gluconate, D-ribose, L-arabinose, 2,3butanediol, tryptamine, trigonelline, tricarballylate or putrescine within 10 days. Malonate is utilized by $78 \%$ of the strains, L-phenylalanine by $89 \%$, 4-hydroxybenzoate by $89 \%$, ethanol by $22 \%$, L-ornithine by $56 \%$ and 
gentisate by $11 \%$. For most strains, growth on 4aminobutyrate or glutarate is not reproducible or is delayed (7-10 days).

The strains studied were isolated exclusively from human clinical specimens (blood, urine, sputum, vaginal swab, throat swab) (Supplementary Table S1 in IJSEM Online). The type strain, NIPH $2150^{\mathrm{T}} \quad\left(=\mathrm{RUH} \quad 422^{\mathrm{T}}=\right.$ CCUG $51248^{\mathrm{T}}=$ CCM $7267^{\mathrm{T}}=1271^{\mathrm{T}}$ ), was isolated in 1978 from the urine of a patient in Leiden University Hospital, The Netherlands (Bouvet \& Jeanjean, 1989). The type strain grows on malonate, L-phenylalanine, L-ornithine, gentisate and quinate, but does not utilize ethanol or L-glutarate.

\section{Acknowledgements}

We thank all those who generously provided strains (listed in Supplementary Table S1). A. N. was supported by grant no. MSM 0021620812 from the Czech Ministry of Education, Youth and Sports. T. De B. is indebted to the Fund for Scientific Research Flanders (FWO) for a position as postdoctoral fellow. Part of this study was presented at the 14th European Congress of Clinical Microbiology and Infectious Diseases (Prague, Czech Republic) in 2004 (abstract P1855) and at the 6th International Symposium on the Biology of Acinetobacter (Dublin, Ireland) in 2004 (abstract D2).

\section{References}

Baumann, P., Doudoroff, M. \& Stanier, R. Y. (1968). A study of the Moraxella group. II. Oxidative-negative species (genus Acinetobacter). J Bacteriol 95, 1520-1541.

Bouvet, P. J. M. \& Grimont, P. A. D. (1986). Taxonomy of the genus Acinetobacter with the recognition of Acinetobacter baumannii sp. nov., Acinetobacter haemolyticus sp. nov., Acinetobacter johnsonii sp. nov., and Acinetobacter junii sp. nov. and emended descriptions of Acinetobacter calcoaceticus and Acinetobacter lwoffii. Int J Syst Bacteriol 36, 228-240.

Bouvet, P. J. M. \& Grimont, P. A. D. (1987). Identification and biotyping of clinical isolates of Acinetobacter. Ann Inst Pasteur Microbiol 138, 569-578.

Bouvet, P. J. M. \& Jeanjean, S. (1989). Delineation of new proteolytic genomic species in the genus Acinetobacter. Res Microbiol 140, 291299.

Carr, E. L., Kämpfer, P., Patel, B. K. C., Gürtler, V. \& Seviour, R. J. (2003). Seven novel species of Acinetobacter isolated from activated sludge. Int J Syst Evol Microbiol 53, 953-963.

Cruze, J. A., Singer, J. T. \& Finnerty, W. R. (1979). Conditions for quantitative transformation in Acinetobacter calcoaceticus. Curr Microbiol 3, 129-132.

Dijkshoorn, L., van Harsselaar, B., Tjernberg, I., Bouvet, P. J. M. \& Vaneechoutte, M. (1998). Evaluation of amplified ribosomal DNA restriction analysis for identification of Acinetobacter genomic species. Syst Appl Microbiol 21, 33-39.

Dijkshoorn, L., Nemec, A. \& Seifert, H. (2007). An increasing threat in the hospital: multidrug-resistant Acinetobacter baumannii. Nat Rev Microbiol 5, 939-951.

Gerner-Smidt, P., Tjernberg, I. \& Ursing, J. (1991). Reliability of phenotypic tests for identification of Acinetobacter species. J Clin Microbiol 29, 277-282.

Janssen, P., Maquelin, K., Coopman, R., Tjernberg, I., Bouvet, P., Kersters, K. \& Dijkshoorn, L. (1997). Discrimination of Acinetobacter genomic species by AFLP fingerprinting. Int J Syst Bacteriol 47, $1179-1187$.

Jukes, T. H. \& Cantor, C. R. (1969). Evolution of protein molecules. In Mammalian Protein Metabolism, vol. 3, pp. 21-132. Edited by $\mathrm{H}$. N. Munro. New York: Academic Press.

Juni, E. (1972). Interspecies transformation of Acinetobacter: genetic evidence for a ubiquitous genus. J Bacteriol 112, 917-931.

La Scola, B., Gundi, V. A., Khamis, A. \& Raoult, D. (2006). Sequencing of the $r p o B$ gene and flanking spacers for molecular identification of Acinetobacter species. J Clin Microbiol 44, 827-832.

Lehmann, V. (1973). Haemolytic activity of various strains of Acinetobacter. Acta Pathol Microbiol Scand [B] Microbiol Immunol 81, 427-432.

Nemec, A., Dijkshoorn, L. \& Ježek, P. (2000). Recognition of two novel phenons of the genus Acinetobacter among non-glucoseacidifying isolates from human specimens. J Clin Microbiol 38, 3937-3941.

Nemec, A., De Baere, T., Tjernberg, I., Vaneechoutte, M., van der Reijden, T. J. K. \& Dijkshoorn, L. (2001). Acinetobacter ursingii sp. nov. and Acinetobacter schindleri sp. nov., isolated from human clinical specimens. Int J Syst Evol Microbiol 51, 1891-1899.

Nemec, A., Dijkshoorn, L., Cleenwerck, I., De Baere, T., Janssens, D., Van Der Reijden, T. J., Ježek, P. \& Vaneechoutte, M. (2003). Acinetobacter parvus sp. nov., a small-colony-forming species isolated from human clinical specimens. Int J Syst Evol Microbiol 53, 1563-1567.

Seifert, H., Dijkshoorn, L., Gerner-Smidt, P., Pelzer, N., Tjernberg, I. \& Vaneechoutte, M. (1997). Distribution of Acinetobacter species on human skin: comparison of phenotypic and genotypic identification methods. J Clin Microbiol 35, 2819-2825.

Tjernberg, I. \& Ursing, J. (1989). Clinical strains of Acinetobacter classified by DNA-DNA hybridization. APMIS 97, 595-605.

Vaneechoutte, M., Tjernberg, I., Baldi, F., Pepi, M., Fani, R., Sullivan, E. R., van der Toorn, J. \& Dijkshoorn, L. (1999). Oil-degrading Acinetobacter strain RAG-1 and strains described as 'Acinetobacter venetianus sp. nov.' belong to the same genomic species. Res Microbiol 150, 69-73.

Vaneechoutte, M., De Baere, T., Nemec, A., Musílek, M., van der Reijden, T. J. K. \& Dijkshoorn, L. (2008). Reclassification of Acinetobacter grimontii Carr et al. 2003 as a later synonym of Acinetobacter junii Bouvet and Grimont 1986. Int J Syst Evol Microbiol 58, 937-940. 